\title{
Application of Task-driven Method in Cost Accounting Teaching
}

\author{
Yingjuan Wang \\ Wuhan Technology and Business University, School of Management, Wuhan 430065, Hubei, China \\ 478618115@qq.com
}

\begin{abstract}
Cost accounting is a core course of accounting major with strong theory and practice. Because of its characteristics of many calculations, many formulas, and cross content, it has increased the difficulty of teaching. This article combines the relevant content of the cost accounting course to explore how to use the Task-driven Method in the teaching process to help students master relevant knowledge points and improve teaching effects.
\end{abstract}

Keywords: Cost accounting, Task-driven Method, Teaching

\section{INTRODUCTION}

"Task-driven Method" is a teaching method based on constructivist learning theory. It transforms the teaching concept of teaching knowledge in the past into multi-dimensional and interactive teaching with problem solving and task completion method. It is required that in the teaching process, taking the completion of specific tasks as clues, the "task-driven method" is required to cleverly hide the teaching content in each task during the teaching process [1], so that the students are in an active learning state, driven by a strong problem motive, through active application of learning resources, independent exploration and interactive and collaborative learning are conducted. In the learning process, students become the center of teaching, and teachers gradually retreat from their dominant position to play the role of learning partners to help students complete their tasks [2]. In this process, students must use their knowledge to solve various problems encountered, so as to effectively improve their professional abilities. The cost accounting course is the core course of the accounting profession. It is a subject worthy of serious study by accounting teachers in colleges and universities to transform students from passive students into active learning skills.

\section{THE SIGNIFICANCE OF APPLYING TASK-DRIVEN METHOD IN COST ACCOUNTING TEACHING}

\subsection{Conducive to the development of students' comprehensive professional ability}

Comprehensive professional ability refers to the synthesis of multiple abilities that must be possessed in a certain occupation and displayed in the professional activity. The individual classifies the knowledge, skills and attitudes learned in a specific professional activity or situation. The ability to complete certain professional tasks formed by migration and integration. It is not a single capability, nor is it a mechanical addition of irrelevant isolated capabilities, but an organic whole that is interconnected and influenced by each other, and is a "synthesis" of various capabilities. This ability includes not only skills, but also other conditions required for competence and competence, such as ideological character, professional ethics, scientific and cultural foundation, humanistic literacy, professional ability, physical and mental health requirements, any of which is an isolated ability. The elements are difficult to complete professional activities, it is the integration of quality factors such as workers' knowledge, skills and attitudes. Using the Task-driven Method can fully mobilize the enthusiasm of students to participate, teaching closely around the relevant knowledge points, decomposing teacher activities and student activities according to the teaching content throughout the course of teaching activities [3], clarifying work tasks, and allowing students in a relaxed and rigorous classroom atmosphere, through their own practice, to acquire knowledge and skills. In the process of completing tasks, students will develop team consciousness and competitive consciousness through group collaboration, and improve students' communication skills.

\subsection{Realize the integrated teaching of theory and practice}

The basic task of higher education is to train high-level professionals with innovative spirit and practical ability. Theory comes from practice, and innovation comes from practice. Practical teaching and theoretical teaching are the unified system of mutual support for undergraduate teaching. Taking the cultivation of students' professional ability as the fundamental goal. Using the school's simulation equipment, especially the school-enterprise 
cooperation platform, arrange students to learn and practice in the enterprise, teachers combine equipment and field teaching, and use the task-driven method. At this site, students explain how to realize the combination of theory and practice. And can use theoretical knowledge to understand the principles of cost accounting, feel the fun of learning to apply, and further promote the enthusiasm of learning.

\subsection{Cultivate students' innovative spirit and cooperation consciousness}

Use task-driven methods to give students autonomy. Teachers change traditional teaching concepts, let go of hands and feet, and give students free space and time to learn [4]. Determine the group, select relevant knowledge points, and then use the task-driven method to carry out group communication activities. This open teaching can stimulate students' interest in learning. Absolutely independent completion has great difficulties. If students' activities are not guided in a timely and correct manner, and comprehensive learning is left in a state of laissez-faire, the quality of comprehensive learning will be reduced, and it is difficult for students to get the expected exercise from the activities [5]. This requires teachers to grant methods in time, lead students to grow in activities, and stimulate students' desire to explore. Teachers should provide students with a stage to show their talents and promote their bold expression, so that they can improve their language expression, information collection, information processing and speculation ability in the fierce collision of ideas and conflicts of thinking.

\section{THE APPLICATION EXAMPLE OF TASK-DRIVEN METHOD IN COST ACCOUNTING TEACHING}

This article takes the collection and distribution of material costs as an example to illustrate the application of the Task-driven Method in the process of cost accounting teaching and learning.

\subsection{Design task}

The main task of this unit is that students can use the variety method to carry out cost accounting for production enterprises. In order to accomplish this task, a small bicycle tire factory case was designed. By watching related videos, students can have a perceptual understanding and connect the theoretical knowledge learned with the actual work of the enterprise. After watching the related video, the teacher arranged the carefully designed small bicycle tire factory case as a task. The students started from collecting cost accounting materials, allocating element expenses, preparing accounting vouchers, registering cost expense accounts, and calculating various product costs. 3. Prepare cost reports and conduct cost analysis. On the basis of grasping the overall goal of teaching, the overall goal is subdivided into small goals.

\subsection{Create a situation and propose a task}

Because cost accounting is a complex part of knowledge calculation, it is difficult for many students to clarify the ins and outs of the data. It adopts the task-driven method, and calculates the product cost of the enterprise as a general task. In order to complete this task, what should the enterprise do every step Teachers guide students to put forward sub-tasks, which is helpful for students to master the enterprise cost accounting process and experience a sense of accomplishment in the process of completing tasks. For example, in the task of collecting and distributing material expenses, it is necessary to prepare accounting vouchers based on the original vouchers for the students to perform specific operations. The picking list only has a quantity and no amount, and it is not possible to directly prepare accounting vouchers based on the original vouchers. Teachers need to further enlighten how to complete this task based on the raw material account, receipt, and picklist.

\subsection{Guide students to analyze tasks}

After giving the task, the teacher should not rush to explain it. Task analysis is a necessary process. The teacher guides the students to decompose the task and find the key points to solve the problem. And point out what knowledge should be used to complete the task, so that students can clearly understand the learning objectives, apply the theoretical knowledge learned to practice. The collection and distribution of material costs can be divided into the following specific tasks: 1 . The production department issues a pick list based on the production plan and design budget for materials, which are filled out by the statistician. The content must be comprehensive, true, accurate, and received Use the bill of materials to fill out the product batch number according to the production plan, as the basis for the cost reduction, to pick a single triple, workshop statistics, financial, and warehouse. 2. The designated personnel in the production workshop shall receive the raw materials from the warehousing department in the material receiving direction. 3. The warehouse manager checks whether the document procedures are complete. The compliant will issue the raw materials, and count and record the quantity of the raw materials in person. Except for the single joint return unit, the remaining two joints will be received by the warehouse, one of which will be stored and the other will be sent to the finance department. 4. At the end of the month, the full-time personnel of each material-using unit will summarize according to various receipt and return documents, and the cost accountant of the accounting department will summarize the amounts and prepare a summary table of the issuing documents. 5 . Determine the total amount of materials received this month, 
and the material costs shared by several products need to be distributed among several products to prepare a material cost allocation table. 6. Prepare accounting vouchers according to the material cost allocation table. 7. According to the accounting vouchers, register the production cost detail account and the relevant expense detail account. 8. At the end of the month, the accounting staff and warehouse managers counted the inventory and counted the physical objects, so that the accounts were consistent. If a discrepancy is found, the financial department should investigate the cause and deal with it in a timely manner. 9. Evaluate the material cost allocation method selected by the small bicycle tire factory, and put forward suggestions for improvement.

\subsection{Complete tasks autonomously}

The students are divided into six groups, and each group chooses a team leader to be responsible for the specific work. The Task-driven Method emphasizes the entire process of students' independent exploration and personally completing tasks in order to cultivate students' ability to acquire knowledge and skills by using exploratory learning methods and the ability to cooperate with others. Therefore, teachers try not to tell students how to solve the problems they face. For example, when preparing a summary table of issued material vouchers, students can only summarize the total amount of issued materials according to the picking list, but cannot determine the amount of issued materials. Teachers need to inspire students to use the knowledge points of learned inventory to issue pricing Students provide clues or resources to solve problems, and students are grouped to complete tasks independently. The task designed by the teacher should have a certain degree of openness. After the collection and distribution of material costs are completed according to the method selected by the bicycle tire factory, the selected material cost allocation method is evaluated and suggestions for improvement are proposed.

\subsection{Summary of communication evaluation tasks}

Evaluation can use a combination of self-evaluation, inter-evaluation within groups, inter-evaluation between groups, teacher comments and other evaluation methods. While affirming the students' achievements, it pointed out the existing problems and areas for improvement. While inspiring students' enthusiasm and enhancing confidence, it also allowed students to learn the endless truth, and greaterly stimulated their desire for knowledge, so that students can learn through progressiveness. And gradually achieve the goal. The student evaluation praises the students who have sufficient reasons and are good at expressing their opinions in the selection of the material cost allocation method; praise the best students who have completed this group. Let the student representatives summarize the lessons of this class. The teacher summarizes the main content of the class.

\section{MATTERS NEEDING ATTENTION IN TASK-DRIVEN METHOD IN COST ACCOUNTING CLASSROOM ORGANIZATION}

\subsection{Choose the right teaching content}

Use the Task-driven Method to teach cost accounting courses. Through "doing middle school" and mobilizing the enthusiasm of students through specific tasks, instructors should have good organizational skills, good logical thinking skills, good reflection skills, and rich practical knowledge. Students should With active thinking, good performance and strong practical ability, under the guidance of teachers, students' ability will gradually improve. For example, the collection of material costs and the distribution of teaching content, if directly explained in the traditional classroom, the teacher's effort is not effective, and the students can't even sleep. The task-driven method is not suitable for all chapters. The task-driven method can be used in the cost accounting course as follows: 1. Collection and distribution of material costs; 2. Collection and distribution of labor costs; 3. Other element costs Collection and distribution; 4. Collection and distribution of auxiliary production costs; 5 . Collection and distribution of manufacturing costs; 6 . Variety method; 7. Batch method; 8 . Step-by-step step-by-step method; 9. Parallel settlement Turn to step method; 10. Classification method.

\subsection{Carefully design classroom tasks}

When designing "tasks", we should pay attention to the characteristics of cost accounting courses, pay attention to the differences in students' cognitive characteristics and acceptability, and fully consider the individual differences of students. We must divide the learning objectives into different levels and target students at different levels. Propose appropriate basic goals, development goals and open goals, and design a "task" with a certain capacity and a certain gradient on this basis, requiring all students to complete the small tasks corresponding to the basic goals, and the thoughtful students then complete the next need The tasks corresponding to the development goals that can only be accomplished through hard work, and students who have learned to be creative should also continue to complete the open tasks that follow. For example, the teaching task is to collect and distribute material costs. The bicycle tire factory uses a fixed consumption proportional distribution method to allocate material costs. Teachers guide students to discuss. The basic task is whether to agree with this method and whether there is a more suitable allocation of enterprise material costs. Methods to help companies make suggestions and choose appropriate methods to improve the 
accuracy of allocation. Is it suitable for all companies to improve the task? Is it suitable for the fixed consumption ratio method? There is absolutely a planned amount of use for each product. Many companies can calculate the fixed consumption, so some companies' secrets are kept secret, such as the fixed consumption of pharmaceutical factories and beverage factories. You won't get it, so use other allocation methods. Enterprises that make furniture and electronic products do not have the problem of confidentiality of formulas, but there will be deviations between the actual materials and the fixed materials. For example, when making furniture, you should remove the remaining materials and use the available parts. If the quality of the logs is not Well, the less part is taken, and the skills of the workers must be considered in the actual work.

\subsection{Apply other methods to make up for the deficiencies of the Task-driven Method}

The task-driven method can play a huge role in teaching, but the realization of teaching goals is far more than can be accomplished by a single teaching method, and the task-driven method is not applicable to all teaching content and all chapters. Teachers should learn to adapt the teaching objects, teaching environment, teaching content and teaching goals to local conditions and flexibly adopt appropriate teaching methods to make up for the deficiencies of the Task-driven Method. The teaching methods that are more suitable for the characteristics of the cost accounting course include the graphic method and the comparative analysis method. The graphic method has the characteristics of more image, more intuitive and easier to remember than the text. Using icons to classify and summarize will make the messy knowledge point more Organized and clear, students are easy to master. Figure 1 is an illustration of how the author uses the method of explaining finished products and distributing costs between products.

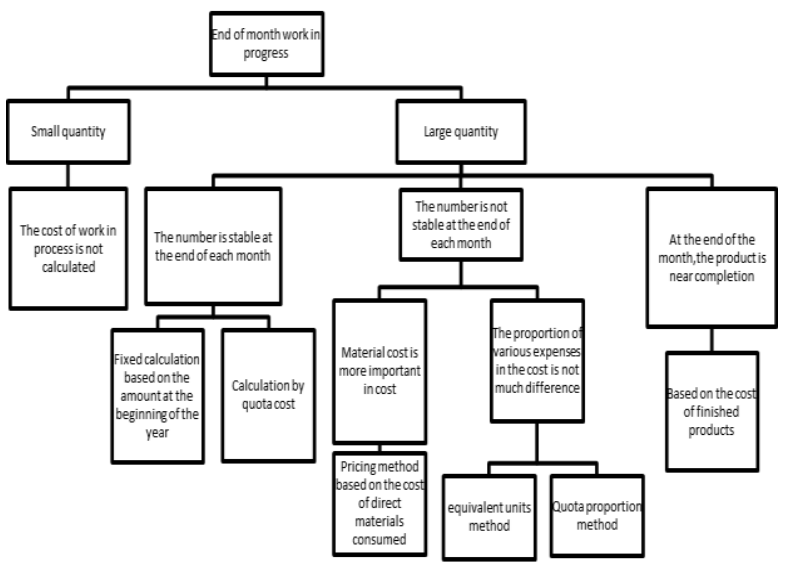

Figure 1 The method of finished products and the distribution of costs between products

The comparison content is listed item by item in the form of tables and charts to make the comparative analysis content more intuitive and conducive to students' mastery. For example, the distribution method of manufacturing costs, using table 1 can intuitively indicate the advantages and disadvantages of the distribution method of manufacturing costs and the scope of application.

Table 1 Distribution method of manufacturing expenses

\begin{tabular}{|l|l|l|l|}
\hline $\begin{array}{l}\text { Manufacturing cost } \\
\text { allocation method } \\
\text { Advantages } \\
\text { Disadvantages }\end{array}$ & Advantages & Disadvantages & Scope of application \\
\hline $\begin{array}{l}\text { Production work } \\
\text { ratio method }\end{array}$ & $\begin{array}{l}\text { It can link the level of } \\
\text { labor productivity with } \\
\text { the amount of product } \\
\text { burden }\end{array}$ & $\begin{array}{l}\text { The statistical work of } \\
\text { production working hours } \\
\text { must be assigned by a } \\
\text { special person; the same } \\
\text { worker produces multiple } \\
\text { products, and the } \\
\text { working hours of the } \\
\text { workers must be } \\
\text { distributed among the } \\
\text { various products, and the } \\
\text { workload is large. }\end{array}$ & Suitable for hourly wages \\
\hline
\end{tabular}




\begin{tabular}{|c|c|c|c|}
\hline $\begin{array}{l}\text { Production worker } \\
\text { wage ratio method }\end{array}$ & $\begin{array}{l}\text { The piece-rate salary of } \\
\text { a product is inversely } \\
\text { proportional to the } \\
\text { machine utilization rate, } \\
\text { which will affect the } \\
\text { reasonable allocation of } \\
\text { expenses }\end{array}$ & $\begin{array}{l}\text { Enterprises that apply } \\
\text { handicraft production and } \\
\text { implement piece-rate } \\
\text { wages }\end{array}$ & \\
\hline $\begin{array}{l}\text { Machine working } \\
\text { hours proportional } \\
\text { method }\end{array}$ & $\begin{array}{l}\text { Data can be obtained } \\
\text { directly from the } \\
\text { measuring instruments } \\
\text { on the machine. }\end{array}$ & $\begin{array}{l}\text { The data of the } \\
\text { measuring instrument } \\
\text { directly affects the } \\
\text { distribution of expenses. } \\
\text { If the measuring } \\
\text { instrument fails, it will } \\
\text { also affect the cost } \\
\text { allocation of the current } \\
\text { month }\end{array}$ & $\begin{array}{l}\text { Applicable to companies that } \\
\text { have a high degree of } \\
\text { mechanization and whose costs } \\
\text { are closely related to the running } \\
\text { time of the machine }\end{array}$ \\
\hline $\begin{array}{l}\text { Annual plan } \\
\text { allocation rate } \\
\text { allocation method }\end{array}$ & $\begin{array}{l}\text { The accounting work is } \\
\text { simple }\end{array}$ & $\begin{array}{l}\text { The non-seasonal } \\
\text { production workshop will } \\
\text { be affected by the } \\
\text { disparity between the } \\
\text { off-season and peak } \\
\text { season production, which } \\
\text { will make the } \\
\text { manufacturing cost of the } \\
\text { unit product cost of each } \\
\text { month fluctuate, which is } \\
\text { not convenient for cost } \\
\text { analysis }\end{array}$ & $\begin{array}{l}\text { Suitable for seasonal production } \\
\text { enterprises, such as down jacket } \\
\text { factory, ice cream factory, etc. }\end{array}$ \\
\hline
\end{tabular}

Auxiliary production cost allocation methods, direct allocation method, interactive allocation method, sequential allocation method, algebraic allocation method, planned allocation method; the method of distributing expenses between finished products and products; the variety method and batch in the product cost calculation method Methods, step-by-step methods, taxonomy, etc. can be taught using comparative analysis. In addition to applying the graphic method and comparative analysis method, you can also use the smooth way: "The cost of materials is significant, production begins to be fully invested, and the materials are calculated during production, and the rest are all returned to the finished product." In each item of product cost, the proportion of material cost is relatively large, and the direct input of direct materials at the beginning of production is when the product is calculated according to the direct material cost consumption method. Under this method, only the material costs that should be borne by the product cost are calculated, and the cost of the completed product includes its Material cost and all other processing costs.

\section{CONCLUSION}

The application of the task-driven method can fully mobilize the enthusiasm and initiative of students to realize the effective transformation of knowledge and skills [6], in order to cultivate high-skilled, high-quality, practical talents that meet the needs of society, are innovative, scientific and practical. The application of task-driven approach to cost accounting teaching practice and exploration not only enables students to master theoretical knowledge and work skills, but also improves teachers' teaching and practical abilities.

\section{REFERENCES}

[1] Huang Dan,Yuan Guanghong,Huang Yunxia.Application of task-driven teaching in rehabilitation medical probation for general medical 
students[J]. Chinese Journal of Medical Education Exploration, 2020, pp. 454-458.

[2] Wang Yali, Wang Pengfei. Application of task-driven method based on fishbone diagram in $\mathrm{NC}$ fault diagnosis and maintenance courses[J]. Industry and Science and Technology Forum, 2019, pp.168-169.

[3] Kuang Bing, He Yulin, Yang Mengjie, et al. Teaching Reform Practice of Organizational Force Analysis Based on Task-driven Method[J]. Education and Teaching Forum, 2018, pp. 130-131.

[4] Yang Huaiyu, Li Donglin. Research on guided task-driven teaching $[\mathrm{J}]$. Education and Teaching Forum, 2018, pp. 150-151.

[5] Liu Caiyan. "Study on the Teaching Path of Medical Translation under the Double Drive of Data and Tasks__ Taking "Methods" Translation Teaching as an Example." Journal of Shanghai University of Technology (Social Science Edition),2019, pp.18-22.

[6] Dou Hongbo. Accounting teaching method [M]. Beijing: China Financial and Economic Publishing House, 2011, pp.181-187. 